\title{
Mission accomplished?
}

\author{
Ulrich Sure ${ }^{1}$
}

Published online: 16 August 2021

(c) The Author(s) 2021

Dear highly esteemed readership and editorial team of $\mathrm{Neu}$ rosurgical Review,

When I took over responsibility as Editor-in-Chief of Neurosurgical Review in 2016, the journal went through a number of difficult, but necessary, changes. After the journal's remarkable success story under the editorship of Helmut Bertalanffy, who had worked to achieve this success, Springer Nature, and more precisely Springer-Verlag $\mathrm{GmbH}$, changed the format of the journal from print to exclusively online. By also changing the managing editorial software, the editorial team introduced a number of new and important features, such as a plagiarism check for any manuscript submitted since 2017 . In the beginning, my personal aim was to further promote the already high quality of the journal and guide it to becoming the journal with the highest impact factor among all the European neurosurgical journals.

To do so, I needed considerable support from local collaborators, and I therefore built up a highly motivated editorial team in Essen. In the past 5 years, this editorial team consisted of numerous important "helping hands and minds." Most recently, the following colleagues have contributed to the success of Neurosurgical Review: Editorial Office, Sandra Braun; and Editorial Assistants (in alphabetical order), PD Dr. Y. Ahmadipour, Dr. L. Barthel, Dr. B Chen, PD Dr. M. Darkwah Oppong, Dr. O. Gembruch, Dr. S. Hetze, PD Dr. R. Jabbarli, PD. Dr. D. Pierscianek, and Dr. L. Rauschenbach. I am most grateful to all these people for their commitment and excellent work. In addition, Springer Verlag GmbH has supported my efforts to improve the quality of Neurosurgical Review by providing a highly qualified and motivated managing team at the publisher end; I would particularly like to highlight the merits of Dr. M. F. Bartels.

With the support of all these people, Neurosurgical Review succeeded in dramatically increasing the number of submitted manuscripts (nearly 4-fold), the number of published Online First articles (2-fold), and the article downloads (2-fold) (see Table 1). These important objectives were achieved thanks to a short and effective review process for all manuscripts submitted.

Case reports and poor-quality papers were rejected immediately, without peer review in many cases. Unfortunately, this means that the overall rejection rate also increased. However,

Table 1 Numbers for Neurosurgical Review 01/2016-06/2021

\begin{tabular}{lllllll}
\hline Year & 2016 & 2017 & 2018 & 2019 & 2020 & 2021 \\
\hline Submissions & 260 & 347 & 437 & 584 & 956 & 484 (until 30/06/2021) \\
Accepted Articles & 56 & 128 & 133 & 155 & 234 & 129 (until 30/06/2021) \\
Articles published Online First & 121 & 129 & 125 & 153 & 225 & 137 (until 30/06/2021) \\
Downloads & 105,152 & 112,660 & 109,332 & 131,962 & 195,194 & 132830 (until 31/05/2021) \\
Impact Factor & $\mathbf{2 . 0 6 0}$ & $\mathbf{2 . 2 5 5}$ & $\mathbf{2 . 5 3 2}$ & $\mathbf{2 . 6 5 4}$ & $\mathbf{3 . 0 4 2}$ & - \\
\hline
\end{tabular}

Ulrich Sure is the Editor-in-Chief of Neurosurgical Review

Ulrich Sure

ulrich.sure@uk-essen.de

1 Department of Neurosurgery and Spine Surgery, University

Hospital Essen, Essen, Germany 
a large number of high-quality manuscripts still remained for the peer review process. Therefore, we are extremely grateful to all our reviewers and the entire international editorial board, since all these people used their expertise to help us to identify the best papers among all manuscripts submitted for publication in Neurosurgical Review. The research for these papers originated on all continents, making the journal even more international than before.

As a consequence, I feel that the quality of papers accepted for publication has further increased over the past 5 years. This impression was recently confirmed by the increase in our impact factor (2020) to 3,042: an all-time high in the history of Neurosurgical Review (see Table 1).

So, in summary, after a demanding and strenuous 5 years as editor, I would like to declare:

\section{My mission is accomplished!}

However, I believe that our originally European, and increasingly international journal, Neurosurgical Review, has an even greater potential for further development. I hope that our readership, as well as all our contributors, agrees with me when I say:

Yes, the mission is accomplished, but not yet finished!
Thank you all once again for your constant, and hopefully continued, support!

Ulrich Sure,

Essen, Germany

Funding Open Access funding enabled and organized by Projekt DEAL.

Open Access This article is licensed under a Creative Commons Attribution 4.0 International License, which permits use, sharing, adaptation, distribution and reproduction in any medium or format, as long as you give appropriate credit to the original author(s) and the source, provide a link to the Creative Commons licence, and indicate if changes were made. The images or other third party material in this article are included in the article's Creative Commons licence, unless indicated otherwise in a credit line to the material. If material is not included in the article's Creative Commons licence and your intended use is not permitted by statutory regulation or exceeds the permitted use, you will need to obtain permission directly from the copyright holder. To view a copy of this licence, visit http://creativecommons.org/licenses/by/4.0/.

Publisher's note Springer Nature remains neutral with regard to jurisdictional claims in published maps and institutional affiliations. 